\title{
OH Group Effect in the Stator of $\beta$-Diketones Arylhydrazone Rotary Switches ${ }^{\dagger}$
}

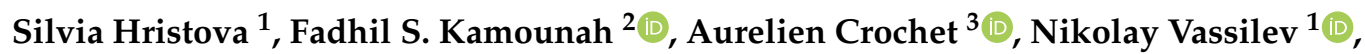 \\ Katharina M. Fromm ${ }^{3}$ (D) and Liudmil Antonov ${ }^{1, *(\mathbb{D})}$ \\ 1 Institute of Organic Chemistry with Centre of Phytochemistry, Bulgarian Academy of Sciences, Acad. G. \\ Bonchev str., bldg. 9, 1113 Sofia, Bulgaria; hristowa.silvia@gmail.com (S.H.); niki@orgchm.bas.bg (N.V.) \\ 2 Department of Chemistry, University of Copenhagen, Universitetsparken 5, DK-2100 Copenhagen $\varnothing$, \\ Denmark; fadil@chem.ku.dk \\ 3 Department of Chemistry, University of Fribourg, Chemin du Musée 9, CH-1700 Fribourg, Switzerland; \\ aurelien.crochet@unifr.ch (A.C.); katharina.fromm@unifr.ch (K.M.F.) \\ * Correspondence: Lantonov@orgchm.bas.bg \\ + Dedicated to Prof. Bernd Giese on Behalf of His 80th Birthday.
}

Received: 14 April 2020; Accepted: 30 April 2020; Published: 4 May 2020

check for updates

\begin{abstract}
The properties of several hydrazon-diketone rotary switches with $\mathrm{OH}$ groups in the stators (2-(2-(2-hydroxy-4-nitrophenyl)hydrazono)-1-phenylbutane-1,3-dione, 2-(2-(2-hydroxyphenyl)hydrazono)-1-phenylbutane-1,3-dione and 2-(2-(4-hydroxyphenyl)hydrazono)1-phenylbutane-1,3-dione) were investigated by molecular spectroscopy (UV-Vis and NMR), DFT calculations (M06-2X/TZVP) and X-ray analysis. The results show that, when the OH group is in ortho position, the $\mathrm{E}^{\prime}$ and $\mathrm{Z}^{\prime}$ isomers are preferred in DMSO as a result of a stabilizing intermolecular hydrogen bonding with the solvent. The availability, in addition, of a nitro group in para position increases the possibility of deprotonation of the $\mathrm{OH}$ group in the absence of water. All studied compounds showed a tendency towards formation of associates. The structure of the aggregates was revealed by theoretical calculation and confirmed by X-ray analysis.
\end{abstract}

Keywords: rotary switch; UV-Vis spectroscopy; NMR; DFT; X-ray; aggregation

\section{Introduction}

The hydrazone functional group has found extensive use in medicine [1-6], supramolecular chemistry (molecular switches and chelate ligands) [7-10] and in combinatory chemistry [11-13]. One important facet of hydrazine-group-containing compounds is the fact that upon appropriate substitution they can exist in solution as a mixture of isomers. 1,2,3-tricarbonyl-2-arylhydrazones are a typical example - they are presented in solution as an equilibrated mixture of intramolecularly $H$-bonded $E$ and $Z$ isomers [14-16]. The position of the isomerization equilibrium can be altered by catalytic amounts of acid or base. Upon external stimulation, a controlled switching between the isomers is possible through C-N bond rotation, giving the name "rotary switches". The position of the equilibrium and the switching can be strongly affected by structural modifications, as has already been shown [17-21].

Recently, the spectral properties of $\mathbf{1}$ (Schemes 1 and 2) were studied in respect of the possible tautomerism and $E / Z$ isomerization in solution $[17,22]$. The results show that the availability of the $\mathrm{OH}$ group in the stator does not lead to azo-hydrazone tautomerism as could be expected at a first glimpse. The compound exists as a mixture of isomers of the single ketohydrazone tautomer, as shown in Scheme 1. In DMSO, due to the specific stabilizing effect of the solvent, only the $E^{\prime}$ and $Z^{\prime}$ forms are presented [22,23]. Moreover, the availability of the $\mathrm{OH}$ group leads to some side effects, according 
to the spectral and crystallographic data [22,24]: compound 1 deprotonates at low concentrations in DMSO and aggregates at high concentrations $\left(10^{-4} \mathrm{M}\right.$ and higher), forming linear $\left(E^{\prime}-E^{\prime}\right)$ aggregates.<smiles>CC(=O)C(=Nc1ccc([N+](=O)[O-])cc1O)C(=O)c1ccccc1</smiles>

$1 \mathrm{E}$<smiles>COC(=O)C(=NNc1ccc([N+](=O)[O-])cc1O)C(=O)c1ccccc1</smiles>

$1 \mathrm{E}^{\prime}$<smiles>CC(=O)C(=Nc1ccc([N+](=O)[O-])cc1O)C(=O)c1ccccc1</smiles>

12<smiles>CC(=O)C(=NNc1ccc([N+](=O)[O-])cc1O)C(=O)c1ccccc1</smiles>

$1 Z^{\prime}$

Scheme 1. Conformational isomers of $\mathbf{1}$.

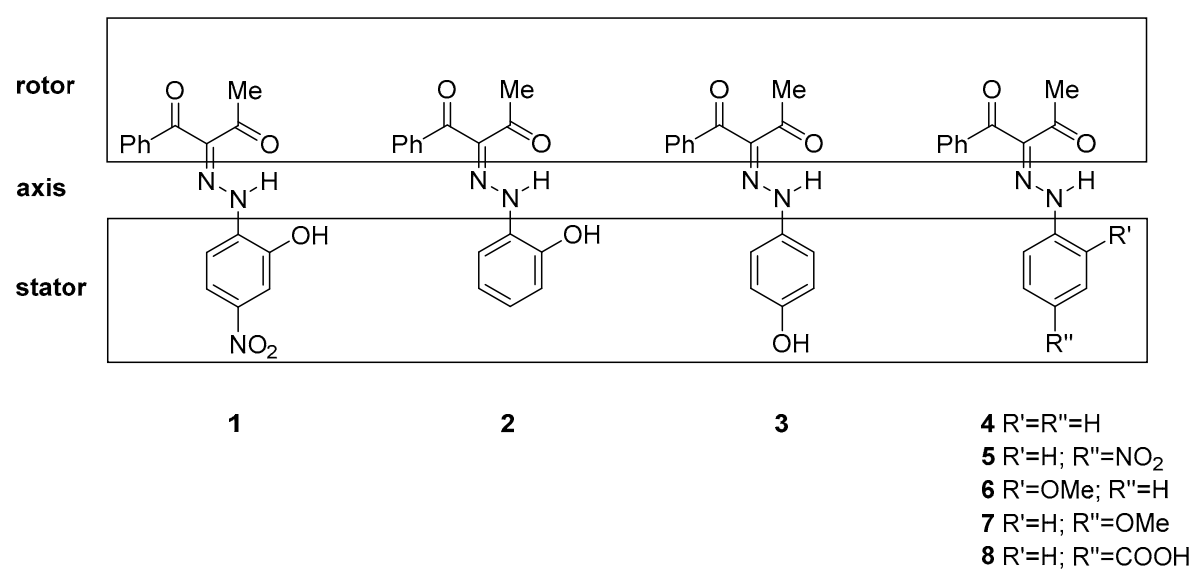

Scheme 2. Sketch of the investigated compounds.

It is an interesting question whether the lack of tautomerism, the existence of the " " " isomers (indicating $E^{\prime}$ and $Z^{\prime}$ forms) and the side effects could be attributed to the strong electron acceptor ability of the nitro group. To answer it, we have studied compounds 2 and 3 , in which two effects could be clarified: the role of the existence of a nitro group ( 2 vs. 1) and of the position of the OH group by itself (2 vs. 3). A combined approach (theoretical calculation, UV-Vis and NMR investigations in solution, and X-ray analysis in solid state) was applied, and the results obtained are presented in the current communication. To best of our knowledge, no such comparative study of 1-3 has been performed before.

\section{Results and Discussion}

The 1,2,3-tricarbonyl-2-arylhydrazones are potentially tautomeric compounds even without an $\mathrm{OH}$ group in the stator. The possible tautomers include ketohydrazone, azoketone and azoenol forms, depending on the substitution [25]. The availability, in addition, of an ortho or para $\mathrm{OH}$ group in the stator makes the tautomeric situation even more complex. The possible tautomers of $\mathbf{2}$ are sketched in Scheme 3 as an example. Theoretical prediction of the stabilities of the individual forms is complicated by the large number of possible conformers. For instance, the tautomer I of $\mathbf{2}$ can be presented as 24 possible isomers (Scheme SI). 
<smiles>CC(=O)C(=O)N=Nc1ccccc1O</smiles>

I<smiles>CC(=O)C(CN=Nc1ccccc1O)c1ccccc1</smiles>

II<smiles>O=C(Cl)C(=NN=CC=C(c1ccccc1)c1ccccc1)c1ccccc1O</smiles>

III<smiles>CCOC(=O)C(C)=C=CN=Nc1ccccc1O</smiles>

IV<smiles>CC(=O)C(Cc1ccccc1)NN=C1C=CC=CC1=O</smiles>

V<smiles>O=C(Cl)C(=O)NN=C1C=CC=CC1=O</smiles>

VI<smiles>CCOC(=O)c1ccccc1</smiles>

VII

Scheme 3. Sketch of the possible tautomeric forms of $\mathbf{2}$ (The same is valid for $\mathbf{1}$ and $\mathbf{3}$ ).

We have shown theoretically that, in the case of $\mathbf{1}$, only tautomer I could be present [22]. As shown in Table S1, the same conclusion can be drawn for $\mathbf{2}$ and $\mathbf{3}$. The theoretical calculations are in agreement with the NMR data in solution [22] and the recent crystallographic data [21]. In analogy, compounds $\mathbf{2}$ and $\mathbf{3}$ also should exist as the same single tautomeric form, stabilized as a mixture of $E$ and $Z$ conformers. The most stable isomers of $\mathbf{2}$ and 3, as predicted in DMSO as an environment, are shown in Figures 1 and 2, respectively.

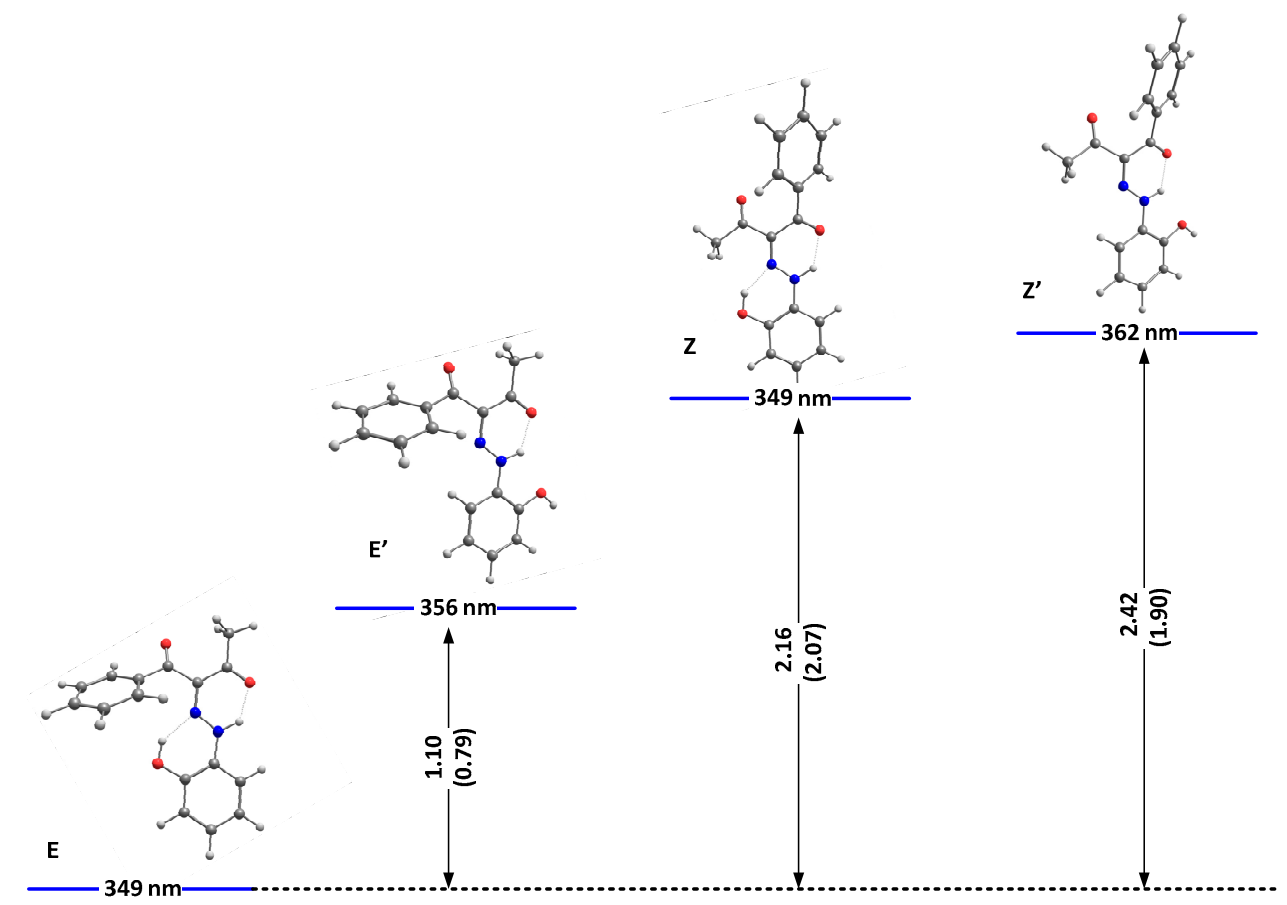

Figure 1. Relative energies (in $\mathrm{kcal} / \mathrm{mole}$ units) and predicted positions of the long-wavelength bands of the most stable isomers of 2(I) in DMSO. The corresponding relative energies for $\mathbf{1}$, taken from [24], are given in brackets. 


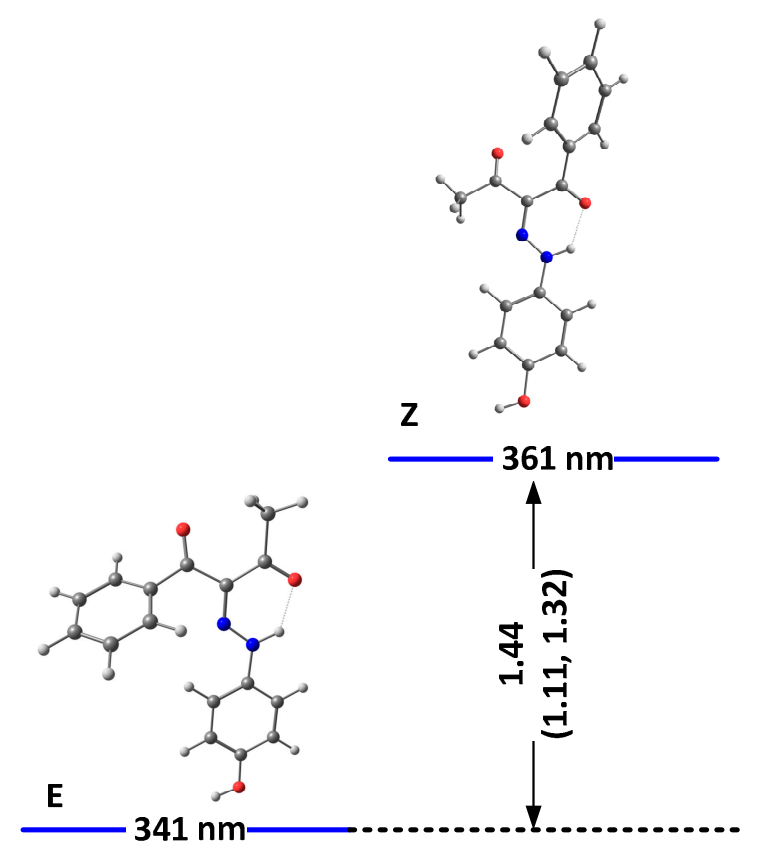

Figure 2. Relative energies (in $\mathrm{kcal} / \mathrm{mole}$ units) and predicted positions of the long-wavelength bands of the most stable isomers of $\mathbf{3}(\mathrm{I})$ in DMSO. The corresponding relative energies for 5, taken from [24] and 4 , are given in brackets.

As seen from the figures, the stabilization is a result of the strength of the formed intramolecular hydrogen bonds. While better proton-attracting ability of MeCO through the NH..OMe determines a better stabilization of the $E$ isomer, additional stabilization through $\mathrm{OH}$.. $\mathrm{N}$ bonding makes the $E / Z$ pairs more stable compared to $E^{\prime} / Z^{\prime}$ in $\mathbf{1}$ and 2 . The effect of the nitro group in $\mathbf{1}$ leads to an overall weak stabilization in the $E / Z$ forms and a more pronounced stability of the " " "isomers. In the case of 3, the effect of the $\mathrm{OH}$ group is limited to a non-hydrogen bonding substituent and leads to stabilization of the $Z$ isomer. The predicted stabilization effect in the series 5 [22], 4 and 3 follows the experimentally observed trend for a destabilization of the $Z$ isomer (molar fractions of $15 \%, 10 \%$ and $5 \%$, correspondingly) going from electron acceptor to electron donor substituents in para position in the stator [19]. Most probably, the absence of the OH..N hydrogen bonding in $\mathrm{E}^{\prime} / \mathrm{Z}^{\prime}$ of 2 and in 3 reduces the steric hindrance between the rotor and the stator, leading to an overall stabilization of the corresponding isomers.

The solvation model used so far describes the solvent as a dielectric medium and does not take into account the possible specific solute-solvent interactions. As known previously in the case of $\mathbf{1}$, the proton of the $\mathrm{OH}$ group interacts with proton-acceptor solvents (such as DMSO), when it is not involved in the intramolecular hydrogen bond with the rotor part, which leads to strong additional stabilization of the " " "isomers. The model of this specific solvent effect is illustrated in Figures 3 and 4 , showing the most stable complexes with DMSO. As can be seen, the interaction between the solvent molecule and the free $\mathrm{OH}$ proton in $E^{\prime}$ and $Z^{\prime}$ leads to their stabilization. Moreover, in $2 \mathrm{E}$ and $2 Z$, there are no conditions for the formation of any $\mathrm{OH} . . \mathrm{O}=\mathrm{SMe}_{2}$ hydrogen bond, and the formed $\mathrm{NH}$ $\ldots \mathrm{O}=\mathrm{SMe}_{2}$ is weak due to the low acidity of the $\mathrm{NH}$ proton and steric effect from adjacent functional groups (Figure 3). The changes in the case of $\mathbf{3}$ are caused by reducing the electron donor ability of the $\mathrm{OH}$ group and hence to a rise in the polarization of the $\mathrm{N}-\mathrm{H}$ bond, leading finally to the stabilization of the $\mathrm{Z}$ isomer. 


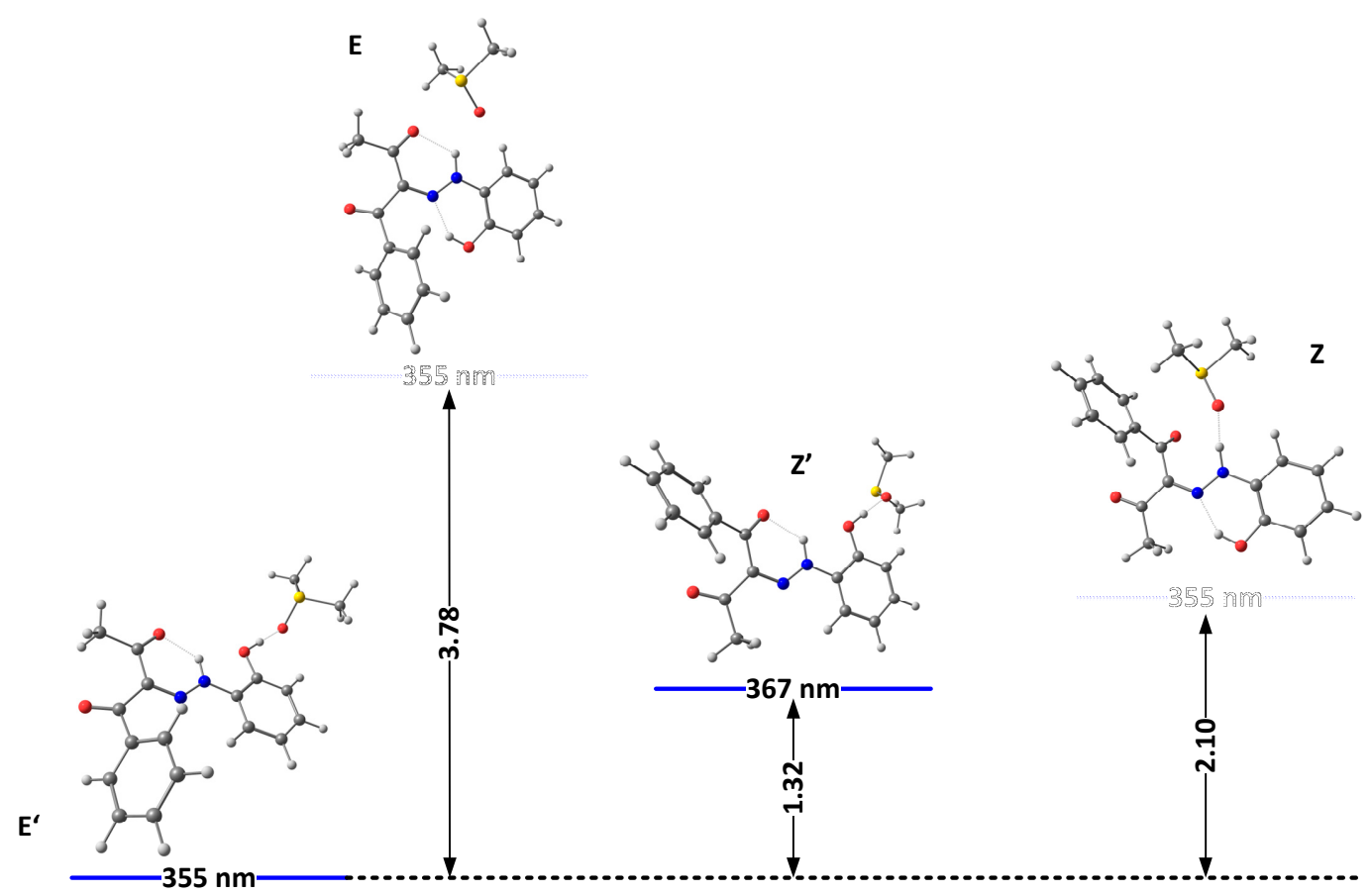

Figure 3. Relative energies (in $\mathrm{kcal} / \mathrm{mole}$ units) and predicted positions of the long-wavelength bands of the most stable isomers of 2(I) in DMSO, accounting for the specific solute-solvent interactions.

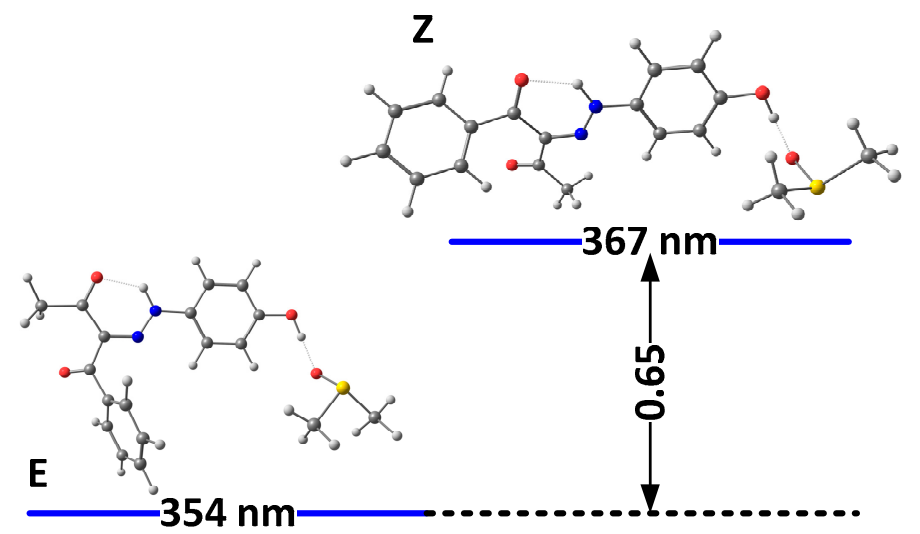

Figure 4. Relative energies (in $\mathrm{kcal} / \mathrm{mole}$ units) and predicted positions of the long-wavelength bands of the most stable isomers of $3(\mathrm{I})$ in DMSO, accounting for the specific solute-solvent interactions.

In addition to the relative stability of the isomers, the predicted positions of the long-wavelength bands in the absorption spectra are shown in Figures 1-4 as well. The absolute values should be considered with care due to the systematic blue shift of the used M06-2X functional. The relative changes indicate, as expected, that it is practically impossible to distinguish between the most stable isomers by means of UV-Vis spectroscopy. The absorption spectra of $\mathbf{2}$ and 3, shown in Figure 5, indicate that there are no substantial changes in the spectral shape upon changing the solvent. This figure strongly supports the hypothesis, in analogy to $\mathbf{1}$; there is no tautomeric equilibrium, because the tautomers of 1-3 have different conjugated systems, and substantially different spectra could be expected upon changing the solvent [26]. It is seen that the observed long-wavelength absorption band consists of two sub-bands, whose intensity slightly varies with the solvent. They can be associated with the most stable isomers according to the theoretical predictions. However, the strong overlapping between them does not allow either precise estimation of the positions of the bands by derivative spectroscopy (Figure S1) nor a quantitative estimation of the isomers' molar fractions [27]. 


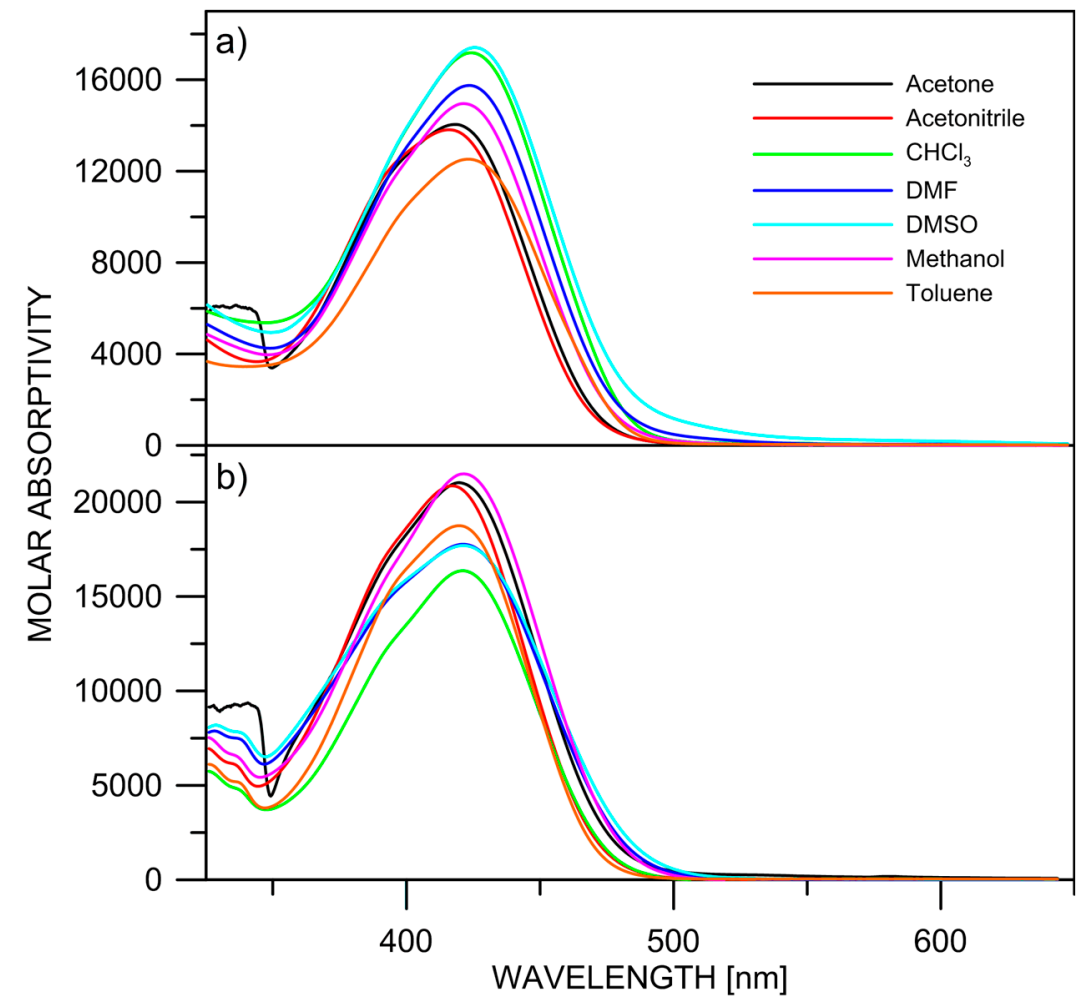

Figure 5. Experimental absorption spectra of $2(\mathbf{a})$ and $\mathbf{3}(\mathbf{b})$ in various solvents.

The conformational isomers existing in solution can be identified and quantified using NMR. Due to their low solubility in acetonitrile, the investigations were performed in DMSO- $d_{6}$. The corresponding ${ }^{1} \mathrm{H}$ NMR spectra of 2 and 3 in DMSO- $d_{6}$ are shown in Figures S2 and S3. The data from the NMR measurements are summarized in Table 1 . The obtained data for chemical shifts can be compared with those for $\mathbf{1}$ [22]. From the ${ }^{1} \mathrm{H}$ NMR spectra of $\mathbf{2}$ and 3, it can be seen that, in both cases, two isomers are present in DMSO- $d_{6}$. The chemical shifts in DMSO- $d_{6}$ for NH for the major and minor form of 2 are at $14.55 \mathrm{ppm}$ and $12.62 \mathrm{ppm}$, and for 3 at $14.48 \mathrm{ppm}$ and $11.42 \mathrm{ppm}$. Based on the NH signals, the ratio between the isomers is $80 \% / 20 \%$ and $45 \% / 55 \%$, respectively for 2 and $3(65 \% / 35 \%$ for 1), which corresponds to $\Delta \mathrm{G}$ values (RT) of $0.36,0.82$ and $-0.11 \mathrm{kcal} / \mathrm{mol}$ for 1-3.

Table 1. ${ }^{1} \mathrm{H}$ and ${ }^{13} \mathrm{C}$ chemical shifts ${ }^{\mathrm{f}}$ of the major form (minor form) of $\mathbf{1}, \mathbf{2}$ and $\mathbf{3}$ in DMSO- $d_{6}$.

\begin{tabular}{|c|c|c|c|}
\hline Compound & 1 & 2 & 3 \\
\hline Conformers (\%) & $65 / 35$ & $80 / 20$ & $45 / 55$ \\
\hline Protons & & ${ }^{1} \mathrm{H}$ chemical shift & \\
\hline 1 & $2.51(2.56)$ & $2.52\left({ }^{a}\right)$ & $2.50(2.44)$ \\
\hline $2^{\prime}$ & - & - & $7.16(7.27)$ \\
\hline $3^{\prime}$ & $7.72(7.70)$ & $6.93\left({ }^{\mathrm{ab}}\right)$ & $6.74(6.76)$ \\
\hline $4^{\prime}$ & - & $7.00\left({ }^{a b}\right)$ & - \\
\hline $5^{\prime}$ & $7.75(7.85)$ & $6.79\left({ }^{a b}\right)$ & $6.74(6.76)$ \\
\hline $6^{\prime}$ & $7.21(7.78)$ & $7.09\left({ }^{a b}\right)$ & $7.16(7.27)$ \\
\hline $2^{\prime \prime}$ & $7.91(7.72)$ & $7.82\left({ }^{a b}\right)$ & $7.78(7.73)$ \\
\hline $3^{\prime \prime}$ & $7.55(7.51)$ & $7.51\left({ }^{a b}\right)$ & $7.50(7.52)$ \\
\hline $4^{\prime \prime}$ & $7.67(7.66)$ & $7.61\left({ }^{a b}\right)$ & $7.59(7.65)$ \\
\hline $\mathrm{NH}$ & $14.14(11.56)^{d}$ & $14.55(12.62)$ & $14.46(11.42)$ \\
\hline $\mathrm{OH}$ & $11.56(11.56)^{d}$ & $10.56(10.56)^{c}$ & $9.58(9.29)$ \\
\hline
\end{tabular}


Table 1. Cont.

\begin{tabular}{|c|c|c|c|}
\hline Compound & 1 & 2 & 3 \\
\hline Carbons & \multicolumn{3}{|c|}{${ }^{13} \mathrm{C}$ chemical shift } \\
\hline 1 & $30.67(25.92)$ & $30.62\left({ }^{b}\right)$ & $30.48(25.31)$ \\
\hline 2 & $198.08\left(^{b}\right)$ & $197.49\left(^{b}\right)$ & $197.03(195.86)^{e}$ \\
\hline 3 & $135.66\left({ }^{b}\right)$ & $133.27\left({ }^{b}\right)$ & $134.21(132.15)^{\mathrm{e}}$ \\
\hline 4 & $191.95\left(^{b}\right)$ & $192.25\left({ }^{b}\right)$ & $194.96(192.13)^{\mathrm{e}}$ \\
\hline $1^{\prime}$ & $136.25\left(^{b}\right)$ & $139.06\left({ }^{b}\right)$ & $136.67(135.54) \mathrm{e}$ \\
\hline $2^{\prime}$ & $145.99\left(^{b}\right)$ & $146.76\left({ }^{b}\right)$ & 118.31 (116.94) \\
\hline $3^{\prime}$ & $110.60\left(^{b}\right)$ & $116.19\left({ }^{b}\right)$ & $116.50(116.27)^{\mathrm{e}}$ \\
\hline $4^{\prime}$ & $143.78\left({ }^{b}\right)$ & $126.38\left({ }^{b}\right)$ & $156.15(154.43)^{e}$ \\
\hline $5^{\prime}$ & $116.78\left(^{b}\right)$ & $120.53\left({ }^{b}\right)$ & $116.50(116.27)^{\mathrm{e}}$ \\
\hline $6^{\prime}$ & $114.08\left(^{b}\right)$ & $114.98\left({ }^{b}\right)$ & 118.31 (116.94) \\
\hline $1^{\prime \prime}$ & $137.96\left({ }^{b}\right)$ & $133.27\left({ }^{b}\right)$ & $139.34(137.06)^{\mathrm{e}}$ \\
\hline $2^{\prime \prime}$ & $130.75\left({ }^{b}\right)$ & $130.49\left({ }^{b}\right)$ & $130.32(128.99)$ \\
\hline $3 "$ & $128.50\left({ }^{b}\right)$ & $128.20\left({ }^{b}\right)$ & $128.16(129.14)$ \\
\hline $4^{\prime \prime}$ & $133.10\left(^{b}\right)$ & $132.30\left({ }^{b}\right)$ & 132.05 (134.03) \\
\hline
\end{tabular}

a Could not be assigned due to overlap; ${ }^{b}$ Could not be assigned due to low intensity; ${ }^{\mathrm{c}}$ The hydroxyl signals of the two forms are overlapped; ${ }^{\mathrm{d}}$ The hydroxyl signals of two forms and the NH signal of minor form are overlapped; ${ }^{\mathrm{e}}$ May be interchanged; ${ }^{\mathrm{f}}$ Numbering according to the Scheme 4 .<smiles>[Y2]c1ccc(N/N=C(\C(C)=O)C(=O)c2ccccc2)c([Y])c1</smiles>

Scheme 4. Numbering of the carbon atoms in $\mathbf{1}\left(\mathrm{X}_{1}=\mathrm{OH}, \mathrm{X}_{2}=\mathrm{NO}_{2}\right), 2\left(\mathrm{X}_{1}=\mathrm{OH}, \mathrm{X}_{2}=\mathrm{H}\right)$ and $3\left(\mathrm{X}_{1}=\mathrm{H}\right.$, $\left.\mathrm{X}_{2}=\mathrm{OH}\right)$.

In analogy to $1[22,24]$ and following the theoretically predicted relative stabilization, it can be concluded that in DMSO there is an equilibrium between $E^{\prime}$ (major) and $Z^{\prime}$ (minor) forms in $\mathbf{2}$ and between $E$ and $Z$ of 3 . The theoretically predicted values for the chemical shifts of the $\mathrm{NH}$ proton of the major and minor form at 2 and 3 , respectively, are $14.61 \mathrm{ppm}\left(2 E^{\prime}\right)$ and $13.67 \mathrm{ppm}\left(2 Z^{\prime}\right)$ and $14.51 \mathrm{ppm}(3 E)$ and $13.44 \mathrm{ppm}(3 Z)$, i.e., the theoretical results are consistent with the experimental ones. Although the NMR determined Gibb's free energies are lower comparing the predicted relative energies $(\Delta \mathrm{E})$, the latter correctly predict the general trend of stabilization of the $Z^{\prime}$ isomers $(\mathbf{3}>\mathbf{1}>\mathbf{2})$ with a good linearity $\left(\Delta \mathrm{G}=1.28 \times \Delta \mathrm{E}-0.98, R^{2}=0.92\right)$.

Three additional factors influence the conformational equilibrium in $\mathbf{2}$ and $\mathbf{3}$ in solution, namely the temperature, the concentration and the water content of the used solvent. As previously shown in the case of $\mathbf{1}$, a spontaneous deprotonation (loss of $\mathrm{OH}$ proton) occurs in diluted solutions of dry proton acceptor solvents [22], leading to a new red-shifted band. Actually, $\mathbf{1}$ is almost fully deprotonated in dry DMSO (Figure S4), while, as seen in Figure 5, deprotonation in 2 is weak and negligible in 3. Obviously, the effect of the nitro group is decisive in this case. Upon addition of water, the equilibrium is fully shifted towards the neutral isomers (Figure S5). According to the theoretical calculations (Table S2), deprotonation does not substantially change the isomers' ratios.

The concentration is an essential factor determining the deprotonation of the investigated compounds. In 2, as in 1, the increase in the concentration leads to a decrease in the content of the deprotonated form, as shown in Figure 6. No such effect is observed in 3. 

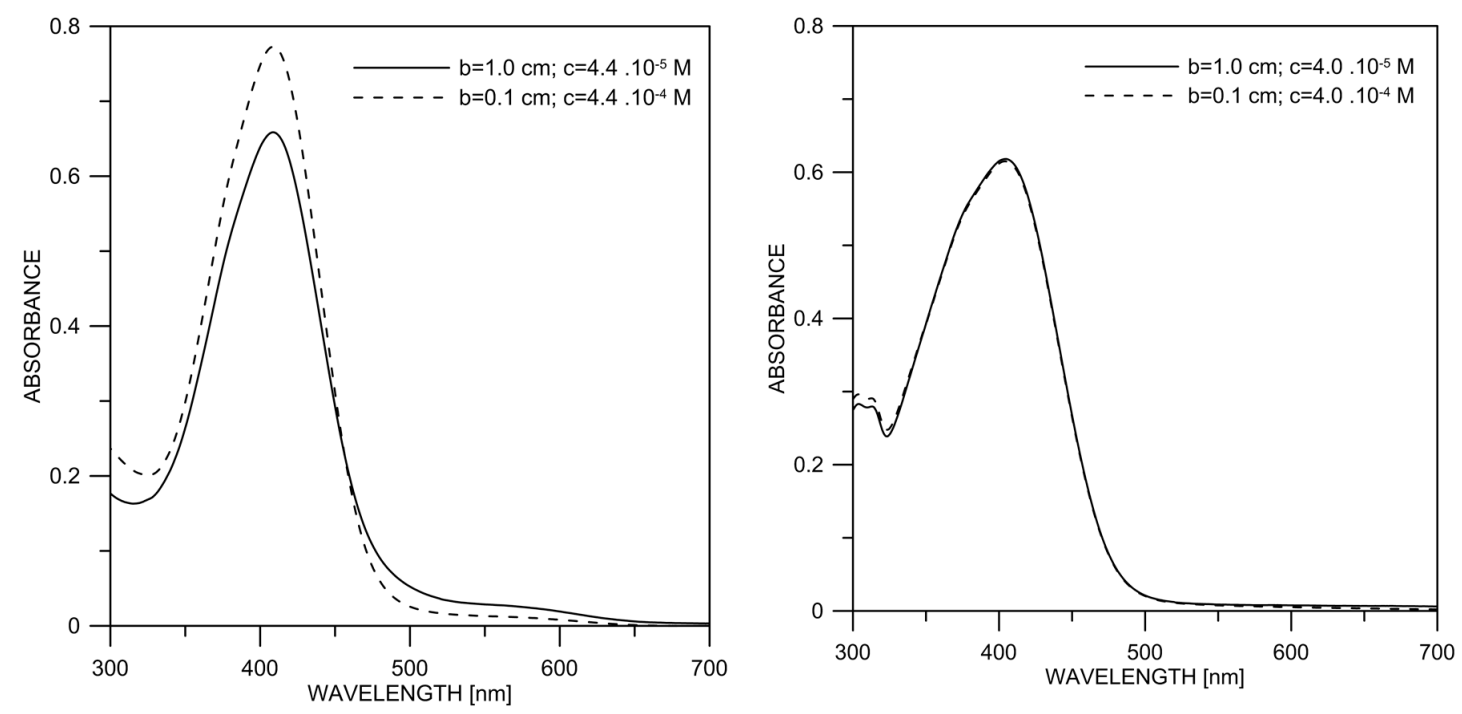

Figure 6. Experimental absorption spectra of 2 (left) and 3 (right) in DMSO as a function of the concentration, keeping the cell thickness $(\mathrm{b}) \times$ concentration $(\mathrm{c})$ constant.

The results above indicate that the association is a possible reason for the observed changes. The theoretical calculations and X-ray data (Figure 7 and Scheme 5) suggest that cyclic aggregates are formed in the case of $\mathbf{2}$. In the solid state, compound $\mathbf{2}$ exists as an $E^{\prime}$ conformer, stabilized via a cyclic dimer. The major difference with $\mathbf{1}$ is in the shape of the aggregate-again, the $E^{\prime}$ form is stabilized in $\mathbf{1}$, but in form of a linear aggregate [24]. The stability of the $E^{\prime}-E^{\prime}$ cyclic dimer in $\mathbf{2}$ is probably due to the stronger proton acceptor properties of the $\mathrm{CH}_{3} \mathrm{CO}$ group compared to the PhCO moiety of $\mathbf{1}$. The formation of aggregates, as in $\mathbf{1}$ [22,24], limits the deprotonation, which explains the observed concentration effects.

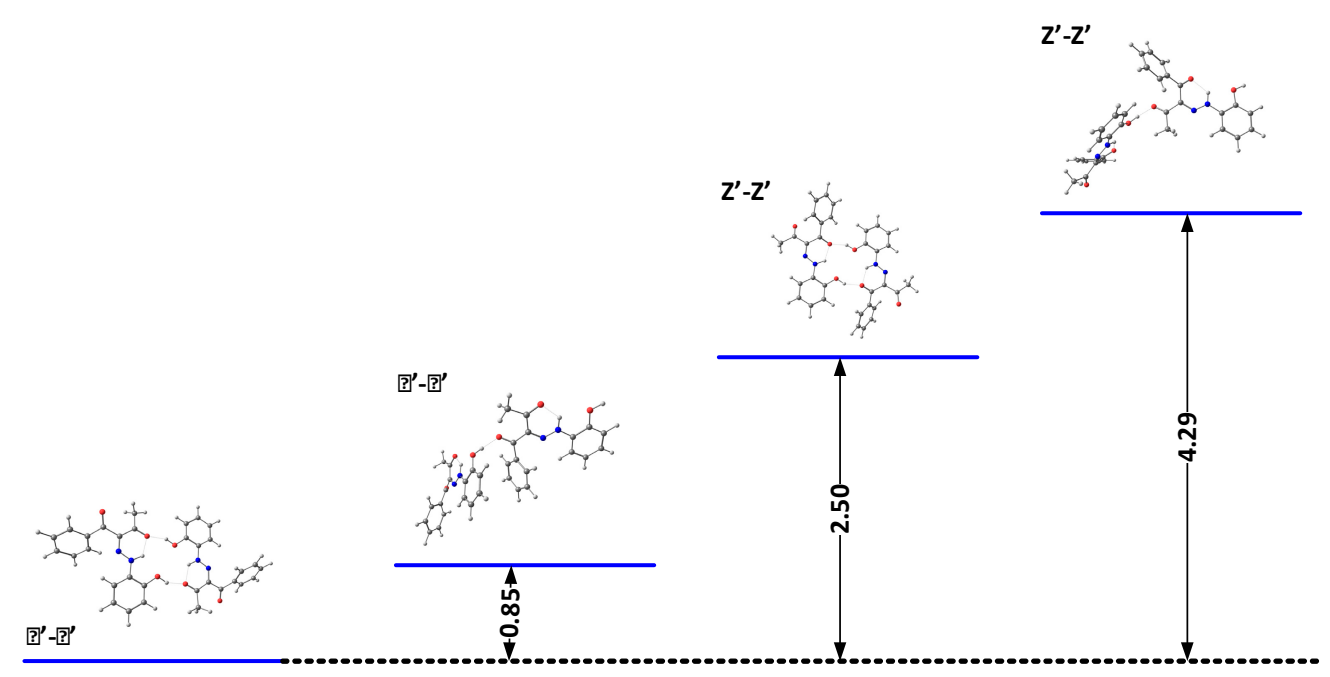

Figure 7. Relative energies (in $\mathrm{kcal} / \mathrm{mol}$ ) of the most stable dimers of 2 in DMSO. 

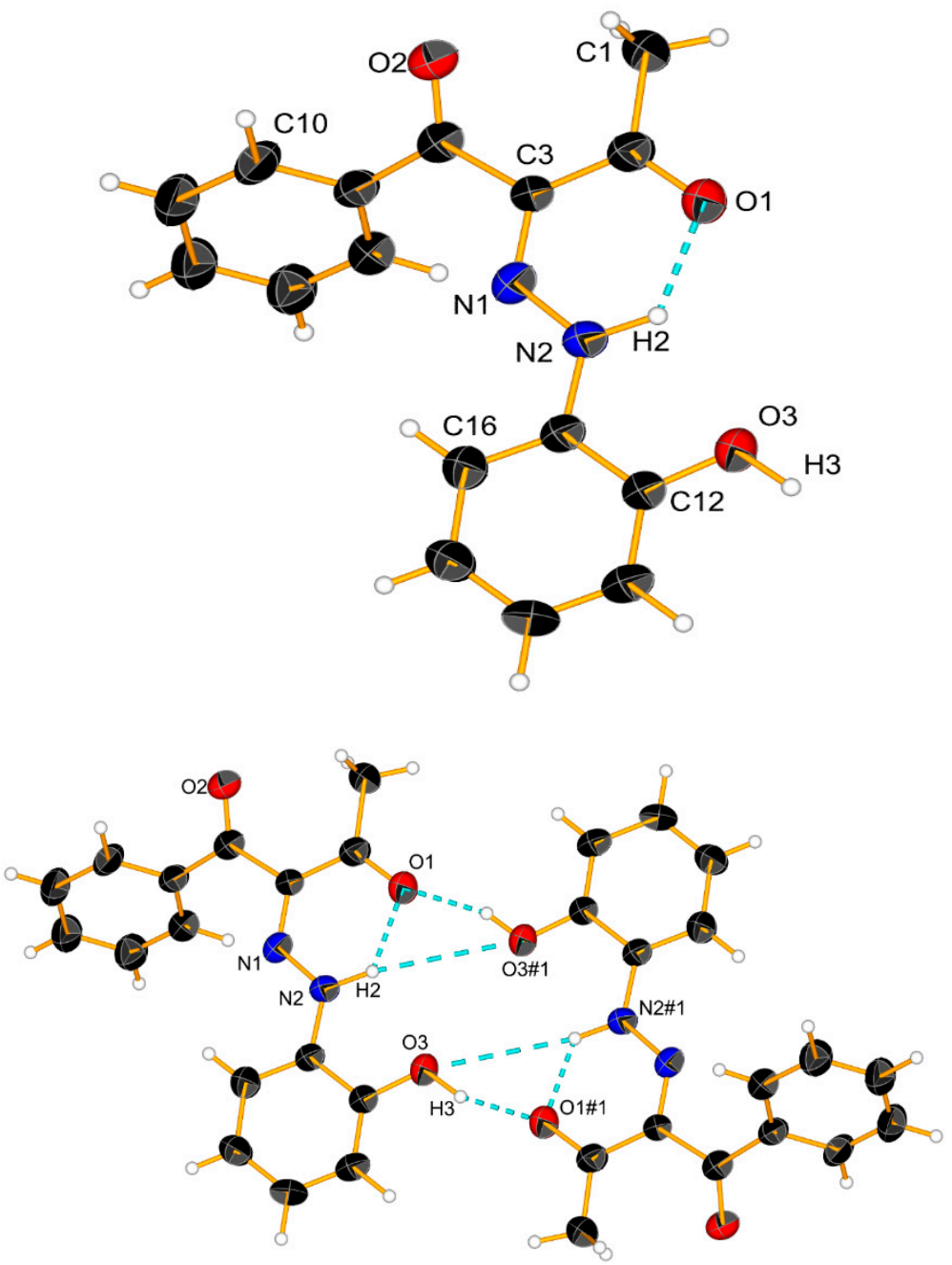

Scheme 5. Crystal structure of 2 and a cyclic dimer model via an intermolecular hydrogen bond. Ellipsoids are drawn with a probability of $50 \%$ and $\mathrm{H}$-bonds are represented as dashed blue lines, $\# 1$ : $2-\mathrm{x}, 1-\mathrm{y}, 2-\mathrm{z}$.

The increase in the concentration did not lead to significant spectral changes in 3 (Figure 6). This is also expected since the $\mathrm{OH}$ group is not polar enough in this particular case, but some linear aggregation cannot be excluded. According to the theoretical simulations (Figure S6) and the crystal structure (Scheme 6), linear E-E aggregates are expected in solution. 


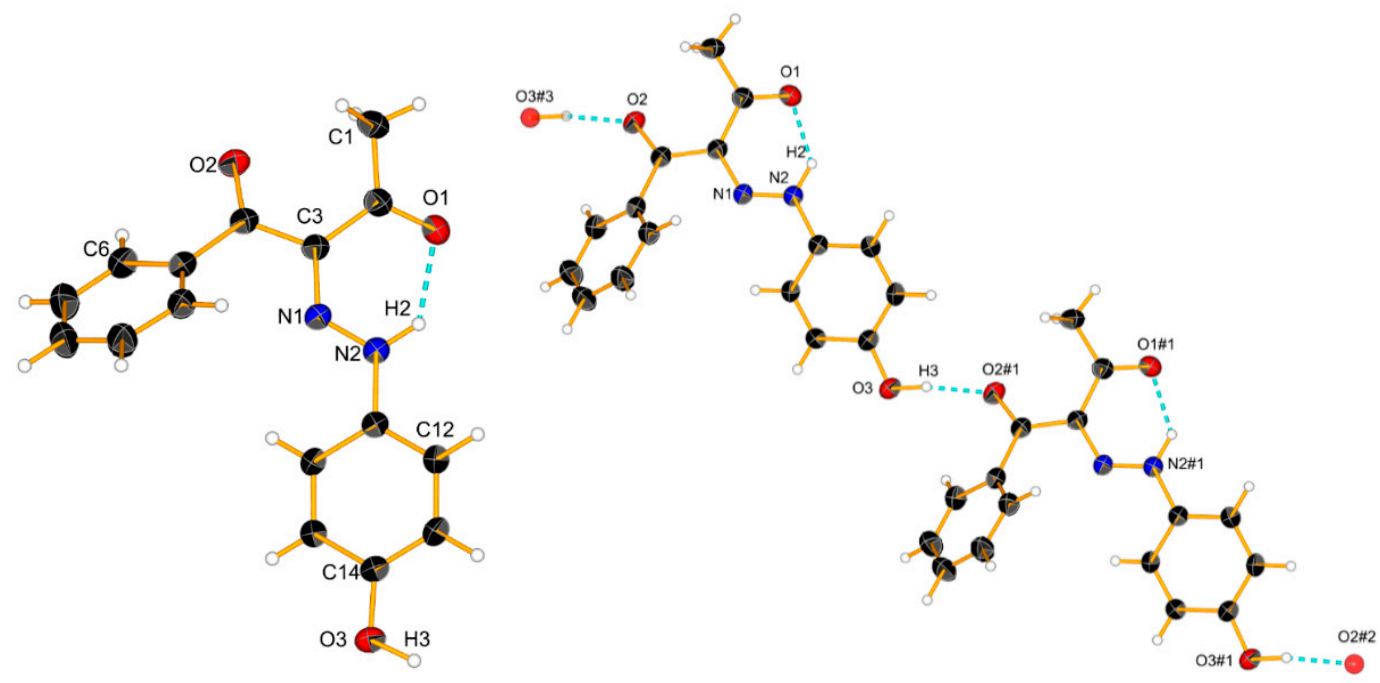

Scheme 6. Crystal structure of 3 and a cyclic dimer model via an intermolecular hydrogen bond. Ellipsoids are drawn with a probability of $30 \%$ and $\mathrm{H}$-bonds are represented as dashed blue lines, \#1: $x-1,1+y, z ; \# 2: x-2, y+2, z ; \# 3: x+1, y-1, z$.

The availability of crystallographic data for the series 1-8 allows qualitative estimation of the strength of the existing intra- and intermolecular hydrogen bonding according to Steiner [28] and Jeffrey [29]. The corresponding bond length and angles are collected in Table 2. According to the classification given in [28], the existing N-H ... O hydrogen bonds are classified as moderate ones using the $\mathrm{H} \ldots$. A and D ... .A distances and the D-H ... A angle. It seems that the strength (at least in solid state) of this bond is almost independent on the substitution in the stator. In the cases where this bond is bifurcated, namely $\mathbf{1}, \mathbf{2}$ and $\mathbf{6}$, the contribution from $\mathrm{N}-\mathrm{H} \ldots \mathrm{O}(=\mathrm{C})$ is the dominant one. This explains why, according to the theoretical calculations using the solvent only as media, the $E$ and $Z$ isomers are always more stable compared to the " " "ones. The data in Table 2 show clearly that the formation of associates through intramolecular hydrogen bonding with strong directionality (D-H ... A angle $>160^{\circ}$ ) has a noticeable stabilizing effect.

Table 2. Parameters of the hydrogen bonds of the studied compounds, taken from their crystallographic data.

\begin{tabular}{|c|c|c|c|c|c|c|c|}
\hline \multirow{2}{*}{ Comp. } & \multirow{2}{*}{\multicolumn{2}{|c|}{ Type D-H ... A Bond }} & \multicolumn{3}{|c|}{ Distances [̊̊] } & \multirow{3}{*}{$\begin{array}{c}\begin{array}{c}\text { D-H ... A } \\
\text { Angle, }\left[{ }^{\circ}\right]\end{array} \\
130.6(7)\end{array}$} & \multirow{3}{*}{ Ref. } \\
\hline & & & \multirow{2}{*}{$\begin{array}{c}\text { D-H } \\
0.896(9)\end{array}$} & \multirow{2}{*}{$\begin{array}{l}\mathbf{H} \ldots \mathbf{A} \\
1.890(7)\end{array}$} & \multirow{2}{*}{$\begin{array}{l}\text { D . . A } \\
2.565(1)\end{array}$} & & \\
\hline \multirow{4}{*}{1} & intramolecular & $\mathrm{N}-\mathrm{H} \ldots \mathrm{O}(=\mathrm{C})$ & & & & & \\
\hline & intermolecular & $\mathrm{N}-\mathrm{H} \ldots \mathrm{O}(-\mathrm{H})$ & & $2.266(9)$ & $2.619(1)$ & $103.1(6)$ & \multirow[t]{3}{*}{ [24] } \\
\hline & (linear dimer) & $\mathrm{O}-\mathrm{H} \ldots \mathrm{O}(=\mathrm{C})$ & $0.85(2)$ & $1.89(2)$ & $2.738(1)$ & $176(1)$ & \\
\hline & intramolecular & $\mathrm{N}-\mathrm{H} \ldots \mathrm{O}(=\mathrm{C})$ & $1.03(3)$ & $1.79(2)$ & $2.567(4)$ & $128(1)$ & \\
\hline \multirow[t]{2}{*}{2} & intermolecular & $\mathrm{N}-\mathrm{H} \ldots \mathrm{O}(-\mathrm{H})$ & & $2.242(8)$ & $2.609(4)$ & $99(1)$ & \multirow[t]{2}{*}{ current work } \\
\hline & (cyclic dimer) & $\mathrm{O}-\mathrm{H} \ldots \mathrm{O}(=\mathrm{C})$ & $0.92(6)$ & $1.79(7)$ & $2.677(4)$ & $161(6)$ & \\
\hline \multirow{3}{*}{2} & intramolecular & $\mathrm{N}-\mathrm{H} \ldots \mathrm{O}(=\mathrm{C})$ & 0.873 & 1.898 & $2.572(1)$ & 132.5 & \multirow{3}{*}[30]{} \\
\hline & intermolecular & $\mathrm{N}-\mathrm{H} \ldots \mathrm{O}(-\mathrm{H})$ & & 2.257 & $2.617(1)$ & 104.5 & \\
\hline & (complex with water) & $\mathrm{O}-\mathrm{H} \ldots \mathrm{OH}_{2}$ & 0.908 & 1.736 & 2.678 & 170.2 & \\
\hline \multirow{2}{*}{3} & $\begin{array}{l}\text { intramolecular } \\
\text { intermolecular }\end{array}$ & $\mathrm{N}-\mathrm{H} \ldots \mathrm{O}(=\mathrm{C})$ & $0.95(2)$ & $1.83(2)$ & $2.565(2)$ & $132(2)$ & \multirow{2}{*}{ current work } \\
\hline & (linear dimer) & $\mathrm{O}-\mathrm{H} \ldots \mathrm{O}(=\mathrm{C})$ & $0.93(3)$ & $1.75(3)$ & $2.667(2)$ & $168(2)$ & \\
\hline 4 & intramolecular & $\mathrm{N}-\mathrm{H} \ldots \mathrm{O}(=\mathrm{C})$ & $0.82(2)$ & $1.93(2)$ & $2.581(2)$ & $135(2)$ & \multirow{4}{*}{ [31] } \\
\hline \multirow{2}{*}{6} & \multirow{2}{*}{ intramolecular } & $\mathrm{N}-\mathrm{H} \ldots \mathrm{O}(=\mathrm{C})$ & \multirow{2}{*}{$0.91(2)$} & $1.85(2)$ & $2.561(2)$ & $133(2)$ & \\
\hline & & N-H $\ldots \mathrm{O}(-\mathrm{Me})$ & & $2.26(2)$ & $2.609(2)$ & 102(1) & \\
\hline 7 & intramolecular & $\mathrm{N}-\mathrm{H} \ldots \mathrm{O}(=\mathrm{C})$ & $0.86(3)$ & $1.89(3)$ & $2.559(3)$ & $133(2)$ & \\
\hline 8 & intramolecular & $\mathrm{N}-\mathrm{H} \ldots \mathrm{O}(=\mathrm{C})$ & 0.935 & 1.866 & $2.594(2)$ & $132(8)$ & [32] \\
\hline
\end{tabular}

The absorption spectra of $\mathbf{2}$ and 3 in DMSO in the temperature range of $20-70{ }^{\circ} \mathrm{C}$ are shown in Figure 8 and Figure S7. In both compounds, it can be seen that with increasing temperature, the absorption maximum of the neutral form $(\sim 400 \mathrm{~nm})$ decreases slightly, while the amount of the deprotonated form absorbing at $\sim 500 \mathrm{~nm}$ increases. 
The result can be interpreted in analogy to 1 [22]. Increasing the temperature leads to the destruction of existing aggregates, which subsequently facilitates the deprotonation of the monomers. The temperature effect was strongest in $\mathbf{1}$ (Figure S8), followed by $\mathbf{2}$ (Figure 8) and lowest for 3 (Figure S7). This indicates that $\mathbf{1}$ has the highest tendency to aggregate again related to the effect of the nitro group. The percentage contents (in \%) of the two neutral isomers were determined by measuring NMR spectra as a function of the temperature (Table S3). It could be thereby shown that the ratio does not change significantly (Figures S9-S11), which probably indicates that they exist in the form of associates in the concentration range used in NMR.

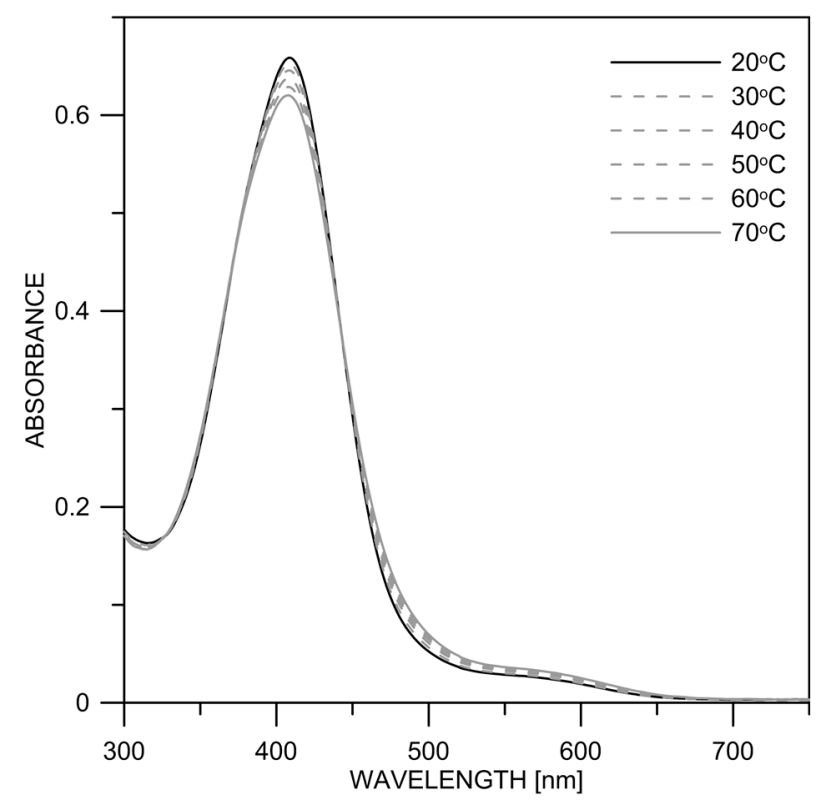

Figure 8. Experimental absorption spectra of 2 in dry DMSO at different temperatures.

\section{Materials and Methods}

\subsection{Synthesis}

Reagents and solvents were analytical grade, purchased from Sigma-Aldrich Chemical Co. and used as received unless otherwise stated. Fluka silica gel/TLC-cards 60778 with fluorescence indicator $254 \mathrm{~nm}$ were used for TLC chromatography. Merck silica gel 60 (0.040-0.063 mm, Merck, Darmstadt, Germany) was used for flash chromatography purification of the products. LC/MS was carried out on a Bruker MicrOTOF-QIII-system with an ESI source with nebulizer 1.2 bar, dry gas $10.0 \mathrm{~L} / \mathrm{min}$, dry temperature $220^{\circ} \mathrm{C}$, capillary $4500 \mathrm{~V}$, and end plate offset $-500 \mathrm{~V}$, Bruker, Hamburg, Germany. The title 2-(2(2-Hydroxy-4-nitrophenyl)hydrazono)-1-phenylbutane-1,2,3-trione 1, 2-[2-(2-Hydroxyphenyl)diazenyl]-1-phenyl-1,3-Butanedione 2 and 2-[2-(4-Hydroxyphenyl)diazenyl]-1phenyl-1,3-Butanedione 3 were synthesized as follows.

\subsubsection{2-(2(2-Hydroxy-4-nitrophenyl)hydrazono)-1-phenylbutane-1,2,3-trione 1}

The synthesis of the compound 1 has been described previously [22].

\subsubsection{2-[2-(2-Hydroxyphenyl)diazenyl]-1-phenyl-1,3-butanedione 2}

A solution of 2-aminophenol $(0.2728 \mathrm{~g}, 2.5 \mathrm{mmol})$ in concentrated hydrochloric acid $(1.5 \mathrm{~mL})$ was cooled in an ice bath for $30 \mathrm{~min}$ with stirring. Sodium nitrite $(0.1725 \mathrm{~g}, 2.5 \mathrm{mmol})$ was added gradually in small portions over $30 \mathrm{~min}$. The diazonium salt was left stirring in the cold for $45 \mathrm{~min}$ and added slowly over $30 \mathrm{~min}$ into a well-cooled stirred mixture of sodium acetate $(1.5 \mathrm{~g}, 18.3 \mathrm{mmol})$ and 1-phenylbutane-1,3-dione $(0.4061 \mathrm{~g}, 2.5 \mathrm{mmol})$ in absolute ethanol $(15 \mathrm{~mL})$. The mixture was 
stirred in an ice-bath for $3 \mathrm{~h}$, and then left to warm to room temperature over $12 \mathrm{~h}$. The solid was filtered off and washed with water $(3 \times 25 \mathrm{~mL})$ to give a light brown solid. The ethanol portion was evaporated under reduced pressure to give dark brown solid. The combined solids were dissolved in dichloromethane $(30 \mathrm{~mL})$ and washed with water $(3 \times 50 \mathrm{~mL})$ and the organic portion dried over anhydrous sodium sulfate, filtered and the solvent evaporated under reduced pressure to obtain a crude brown solid. This was purified by flash column chromatography using a silica flash column and ethyl acetate-dichloromethane (1:20) as eluent to give the pure compound as a light brown solid (0.48 g, 68\%). HRMS-ESI $(\mathrm{m} / \mathrm{z})$ : $(\mathrm{M}+\mathrm{H})$ calculated for $\mathrm{C}_{16} \mathrm{H}_{14} \mathrm{~N}_{2} \mathrm{O}_{3}, 282.1004$; found 282.1084.

\subsubsection{2-[2-(4-Hydroxyphenyl)diazenyl]-1-phenyl-1,3-butanedione 3}

A solution of 4-aminophenol $(0.2728 \mathrm{~g}, 2.5 \mathrm{mmol})$ in concentrated hydrochloric acid $(1.5 \mathrm{~mL})$ was cooled in an ice bath for $30 \mathrm{~min}$ with stirring. Sodium nitrite $(0.1725 \mathrm{~g}, 2.5 \mathrm{mmol})$ was added gradually in small portions over $30 \mathrm{~min}$. The diazonium salt was left stirring in the cold for $45 \mathrm{~min}$ and added slowly over $30 \mathrm{~min}$ into a well-cooled stirred mixture of sodium acetate $(1.5 \mathrm{~g}, 18.3 \mathrm{mmol})$ and 1-phenylbutane-1,3-dion $(0.4061 \mathrm{~g}, 2.5 \mathrm{mmol})$ in absolute ethanol $(15 \mathrm{~mL})$. The mixture was stirred in an ice bath for $3 \mathrm{~h}$, and then warmed to room temperature over $12 \mathrm{~h}$. The solid was filtered off and washed with water $(3 \times 25 \mathrm{~mL})$ to give a yellow solid. The ethanol portion was evaporated under reduced pressure to give a dark yellow solid. The combined solids were dissolved in dichloromethane $(30 \mathrm{~mL})$ and washed with water $(3 \times 50 \mathrm{~mL})$ and the organic portion was dried over anhydrous sodium sulfate, filtered, and the solvent evaporated under reduced pressure to obtain a crude brown solid. This was purified by flash column chromatography using a silica flash column and ethyl acetate-dichloromethane (1:20) as eluent to give the pure compound as a light-yellow solid $(0.52 \mathrm{~g}$, 74\%). HRMS-ESI $(m / z):(\mathrm{M}+\mathrm{H})$ calculated for $\mathrm{C}_{16} \mathrm{H}_{14} \mathrm{~N}_{2} \mathrm{O}_{3}$, 282.1004; found 282.1066.

\subsection{Spectral Measurements}

Spectral measurements were performed on a Jasco V-570 UV-Vis-NIR spectrophotometer, equipped with a thermostatic cell holder (using Huber MPC-K6 thermostat with precision $1{ }^{\circ} \mathrm{C}$ ), in spectral grade solvents.

The ${ }^{1} \mathrm{H}-\mathrm{NMR}$ and ${ }^{13} \mathrm{C}-\mathrm{NMR}$ spectra were recorded at $600 \mathrm{MHz}$ and $150 \mathrm{MHz}$ or $400 \mathrm{MHz}$ and $100 \mathrm{MHz}$ on a Bruker Avance II+ 600 or Bruker Avance III 400 spectrometer using $\mathrm{CDCl}_{3}$ or DMSO- $d_{6}$ as a solvent and TMS as internal standard.

\subsection{X-ray Measurements}

Single crystals of $\mathrm{C}_{16} \mathrm{H}_{14} \mathrm{~N}_{2} \mathrm{O}_{3}$ (2) were obtained from a mixture of ethanol:water (5:1) by slow evaporation. A suitable single crystal was selected and mounted on a loop with oil and measured on a STOE IPDS 2T diffractometer. The crystal was kept at $200 \mathrm{~K}$ during data collection. Using Olex2 [33], the structure was solved with the ShelXT [34] structure solution program using intrinsic phasing and refined with the ShelXL [35] refinement package using least squares minimization. All the crystal structures have been deposited at the CCDC 1858058 (1), 1993960 (2) and 1993961 (3).

Crystal Data for $\mathrm{C}_{16} \mathrm{H}_{14} \mathrm{~N}_{2} \mathrm{O}_{3}(M=282.29 \mathrm{~g} / \mathrm{mol})$ : triclinic, space group $P-1$ (no. 2$), a=5.8853(12)$ $\AA, b=8.0633(16) \AA, c=15.944(3) \AA, \alpha=77.760(15)^{\circ}, \beta=88.887(16)^{\circ}, \gamma=68.978(15)^{\circ}, V=688.9(2) \AA^{3}$, $\mathrm{Z}=2, T=200 \mathrm{~K}, \mu(\mathrm{Cu} \mathrm{K} \alpha)=0.785 \mathrm{~mm}^{-1}$, Dcalc $=1.361 \mathrm{~g} / \mathrm{cm}^{3}, 5325$ reflections measured $\left(14.428^{\circ} \leq 2 \theta\right.$ $\left.\leq 138.228^{\circ}\right), 5365$ unique $\left(R_{\text {int }}=0.0571, R_{\text {sigma }}=0.0392\right)$ which were used in all calculations. The final $R_{1}$ was 0.0712 (I $\left.>4 \mathrm{u}(\mathrm{I})\right)$ and $w R_{2}$ was 0.2505 (all data).

Single crystals of $\mathrm{C}_{16} \mathrm{H}_{14} \mathrm{~N}_{2} \mathrm{O}_{3}$ (3) were obtained from a mixture of ethanol:chloroform:water (10:1:2) by slow evaporation. A suitable single crystal was selected and mounted on a loop with oil and measured on a STOE IPDS 2T diffractometer. The crystal was kept at 298(2) K during data collection. Using Olex2 [33], the structure was solved with the ShelXT [34] structure solution program using intrinsic phasing and refined with the ShelXL [35] refinement package using least squares minimization. 
Crystal Data for $\mathrm{C}_{16} \mathrm{H}_{14} \mathrm{~N}_{2} \mathrm{O}_{3}(M=282.29 \mathrm{~g} / \mathrm{mol})$ : triclinic, space group $P-1$ (no. 2), $a=6.3843(4) \AA$, $b=8.0018(5) \AA, c=15.0129(10) \AA, \alpha=96.235(5)^{\circ}, \beta=101.298(5)^{\circ}, \gamma=107.252(5)^{\circ}, V=706.78(8) \AA^{3}$, $Z=2, T=298(2) \mathrm{K}, \mu(\mathrm{MoK} \alpha)=0.093 \mathrm{~mm}^{-1}$, Dcalc $=1.326 \mathrm{~g} / \mathrm{cm}^{3}, 8242$ reflections measured $\left(2.812^{\circ} \leq\right.$ $\left.2 \theta \leq 52.618^{\circ}\right), 2808$ unique $\left(R_{\text {int }}=0.0164, R_{\text {sigma }}=0.0146\right)$ which were used in all calculations. The final $R_{1}$ was $0.0390(\mathrm{I}>2 \sigma(\mathrm{I}))$ and $w R_{2}$ was 0.1142 (all data).

\subsection{Quantum-Chemical Calculations}

Quantum-chemical calculations were performed using the Gaussian 09 program suite [36]. M06-2X functional $[37,38]$ was used with the TZVP basis set [39]. This fitted hybrid meta-GGA functional with $54 \%$ HF exchange has especially been developed to describe main-group thermochemistry and non-covalent interactions, showing very good results in the prediction of the position of the tautomeric equilibrium in azonaphthols possessing intramolecular hydrogen bonds [40] and in the description of the proton transfer reactions in naphthols [41,42]. All structures were optimized without restrictions, using tight optimization criteria and an ultrafine grid in the computation of two-electron integrals and their derivatives, and the true minima were verified by performing frequency calculations in the corresponding environment. Solvent effects are described by using the Polarizable Continuum Model (the integral equation formalism variant, IEFPCM, as implemented in Gaussian 09) [43]. The absorption spectra of the compounds were predicted using the TD-DFT formalism. TD-DFT calculations were carried out at the same functional and basis set, which is in accordance with conclusions about the effect of the basis set size and the reliability of the spectral predictions [44-46].

\section{Conclusions}

The effect of the position of the $\mathrm{OH}$ group and the availability of a nitro group substitution in the stator was investigated in solution by means of DFT calculations, NMR and UV-Vis spectroscopy. The results indicate that, when the $\mathrm{OH}$ group is in ortho position, the $\mathrm{E}^{\prime}$ and $\mathrm{Z}^{\prime}$ isomers are present in DMSO, stabilized by intermolecular hydrogen bonding with the solvent. The availability, in addition, of a nitro group in para position increases the possibility for deprotonation of the $\mathrm{OH}$ group in the absence of water. In all studied compounds, a clear tendency towards formation of associates is evident. The obtained X-ray data explain the types of the possible homo-aggregates and correspond very well to the theoretical predictions. The obtained results, revealing the effect of the structural modifications in the stator and the influence of the environment, could be useful in the design of new rotary switches.

Supplementary Materials: The following are available online at http://www.mdpi.com/2624-8549/2/2/24/s1. Figure S1: Second derivative spectra of a) 2 and b) 3 in various solvents, Figure S2: ${ }^{1} \mathrm{H}$ NMR spectrum of 2 in DMSO- $d_{6}$, Figure S3: ${ }^{1} \mathrm{H}$ NMR spectrum of 3 in DMSO- $d_{6}$, Figure S4: Absorption spectra of 1, 2 and 3 in dry DMSO and upon base (TEA) addition, Figure S5: Experimental absorption spectra of 1 and $\mathbf{2}$ upon water addition, Figure S6: Relative energies (in kcal/mol) of the most stable dimers of 3 in DMSO, Figure S7: Absorption spectra of $\mathbf{3}$ in DMSO in different temperatures, Figure S8: Absorption spectra of $\mathbf{1}$ in DMSO in different temperatures, Figure S9: ${ }^{1} \mathrm{H}$ NMR spectrum of $\mathbf{1}$ in DMSO at a temperature range of $20^{\circ} \mathrm{C}$ to $70{ }^{\circ} \mathrm{C}$, Figure S10: ${ }^{1} \mathrm{H}$ NMR spectrum of 2 in DMSO at a temperature range of $20^{\circ} \mathrm{C}$ to $70{ }^{\circ} \mathrm{C}$, Figure S11: ${ }^{1} \mathrm{H}$ NMR spectrum of 3 in DMSO at a temperature range of $20^{\circ} \mathrm{C}$ to $70{ }^{\circ} \mathrm{C}$, Table S1: The most stable isomers of I-VII of 2 in gas phase, Table S2: Relative energies (M06-2X/TZVP) of the most stable neutral and deprotonated forms of 1, 2, 3 in kcal/mol units, Table S3: Ratio between $E\left(E^{\prime}\right) / Z\left(Z^{\prime}\right)$ forms in 1, 2 and 3 in the temperature range of $293 \mathrm{~K}-343 \mathrm{~K}$, Scheme SI: Possible conformers of $\mathbf{I}$ and their relative energies (in $\mathrm{kcal} / \mathrm{mol}$, according to quantum-chemical calculations) in acetonitrile.

Author Contributions: Conceptualization, L.A.; methodology, L.A. and N.V.; validation, S.H. and A.C.; formal analysis, S.H. and L.A.; investigation, S.H., F.S.K., N.V. and A.C.; resources, L.A., F.S.K. and K.M.F; data curation, L.A. and K.M.F.; writing — original draft preparation, S.H.; writing—review and editing, L.A., N.V. and K.M.F; supervision, L.A. and K.M.F.; project administration, L.A.; funding acquisition, K.M.F. and L.A. All authors have read and agreed to the published version of the manuscript.

Funding: This research was funded by The Swiss National Science Foundation, Institutional Partnership project IZ74Z0_160515, Bulgarian National Science Fund, project DN09/10 MolRobot, and Bulgarian Ministry of Educations, project DFNP-17-66/26.07.2017.

Acknowledgments: The financial support by Bulgarian Ministry of Educations (project DFNP-17-66/26.07.2017 for support of young scientists), Bulgarian National Science Fund (project DN09/10 MolRobot) and The Swiss National 
Science Foundation (SCOPES Institutional Partnership project IZ74Z0_160515 SupraMedChem@Balkans.Net) is gratefully acknowledged.

Conflicts of Interest: No conflict of interest.

\section{References}

1. Vicini, P.; Zani, F.; Cozzini, P.; Doytchinova, I. Hydrazones of 1,2-benzisothiazole hydrazides: Synthesis, antimicrobial activity and QSAR investigations. Eur. J. Med. Chem. 2002, 37, 553-564. [CrossRef]

2. Loncle, C.; Brunel, M.; Vidal, N.; Dherbomez, M.; Letourneux, Y. Synthesis and antifungal activity of cholesterol-hydrazone derivatives. Eur. J. Med. Chem. 2004, 39, 1067-1071. [CrossRef] [PubMed]

3. Savini, L.; Chiasserini, L.; Travagli, V.; Pellerano, C.; Novellino, E.; Cosentino, S.; Pisano, B. New $\alpha$-(N)-heterocyclichydrazones: Evaluation of anticancer, anti-HIV and antimicrobial activity. Eur. J. Med. Chem. 2004, 39, 113-122. [CrossRef] [PubMed]

4. Cocco, T.; Congiu, C.; Lilliu, V.; Onnis, V. Synthesis and in vitro antitumoral activity of new hydrazinopyrimidine-5-carbonitrile derivatives. Bioorganic Med. Chem. 2006, 14, 366-372. [CrossRef]

5. Masunari, A.; Tavares, C. A new class of nifuroxazide analogues: Synthesis of 5-nitrothiophene derivatives with antimicrobial activity against multidrug-resistant Staphylococcus aureus. Bioorganic Med. Chem. 2007, 15, 4229-4236. [CrossRef]

6. Vicini, P.; Incerti, M.; La Colla, P.; Loddo, R. Anti-HIV evaluation of benzo[d]isothiazole hydrazones. Eur. J. Med. Chem. 2009, 44, 1801-1807. [CrossRef]

7. Lehn, J. From supramolecular chemistry towards constitutional dynamic chemistry and adaptive chemistry. Chem. Soc. Rev. 2007, 36, 151-160. [CrossRef]

8. Lehn, J. Constitutional Dynamic Chemistry: Bridge from Supramolecular Chemistry to Adaptive Chemistry; Barboiu, M., Ed.; Springer: Berlin/Heidelberg, Germany, 2012; Volume 322, pp. 1-32.

9. Lehn, J. Perspectives in Chemistry-Steps towards Complex Matter. Angew. Chem. Int. Ed. 2013, 52, $2836-2850$. [CrossRef]

10. Lygaitis, R.; Getautis, V.; Grazulevicius, J.V. Hole-transporting hydrazones. Chem. Soc. Rev. 2008, 37, 770-788. [CrossRef]

11. Rowan, J.; Cantrill, J.; Cousins, L.; Sanders, M.; Stoddart, F. Dynamic Covalent Chemistry. Angew. Chem. Int. Ed. 2002, 41, 898-952. [CrossRef]

12. Corbett, T.; Leclaire, J.; Vial, L.; West, R.; Wietor, L.; Sanders, M.; Otto, S. Dynamic Combinatorial Chemistry. Chem. Rev. 2006, 106, 3652-3711. [CrossRef] [PubMed]

13. Wilson, J. Dynamic Combinatorial Chemistry. In Drug Discovery, Bioorganic Chemistry, and Materials Science. Edited by Benjamin, L. Miller. Angew. Chem. Int. Ed. 2010, 49, 4011. [CrossRef]

14. Courtot, P.; Pichon, R.; Le Saint, J. Determination du site de chelation chez les arylhydrazones de tricetones et $\mathrm{D}^{\prime} \alpha$-dicetones substituees. Tetrahedron Lett. 1976, 17, 1177-1180. [CrossRef]

15. Courtot, P.; Pichon, R.; Le Saint, J. Photochromisme par isomerisation syn-anti de phenylhydrazones-2- de tricetones-1,2,3 et de dicetones-1,2 substituees. Tetrahedron Lett. 1976, 17, 1181-1184. [CrossRef]

16. Pichon, R.; Le Saint, J.; Courtot, P. Photoisomerisation d'arylhydrazones-2 de dicetones-1,2 substituees en 2. : Mecanisme d'isomerisation thermique de la double liaison C=N. Tetrahedron 1981, 37, 1517-1524. [CrossRef]

17. Mahmudov, K.T.; Rahimov, R.A.; Babanly, M.B.; Hasanov, P.Q.; Pashaev, F.G.; Gasanov, A.G.; Kopylovich, M.N.; Pombeiro, A.J.L. Tautomery and acid-base properties of some azoderivatives of benzoylacetone. J. Mol. Liq. 2011, 162, 84-88. [CrossRef]

18. Kuznik, W.; Kopylovich, M.N.; Amanullayeva, G.I.; Pombeiro, A.J.L.; Reshak, A.; Mahmudov, K.T.; Kityk, I. Role of tautomerism and solvatochromism in UV-VIS spectra of arylhydrazones of $\beta$-diketones. J. Mol. Liq. 2012, 171, 11-15. [CrossRef]

19. Mitchell, A.; Nonhebel, D.C. Spectroscopic studies of tautomeric systems-III. Tetrahedron 1979, 35, $2013-2019$.

20. Su, X.; Aprahamian, I. Hydrazone-based switches, metallo-assemblies and sensors. Chem. Soc. Rev. 2014, 43, 1963-1981. [CrossRef]

21. Gurbanov, A.V.; Kuznetsov, M.L.; Demukhamedova, S.D.; Aliyeva, I.N.; Godjaev, N.M.; Zubkov, F.I.; Mahmudov, K.T.; Pombeiro, A.J.L. Role of substituents on resonance assisted hydrogen bonding vs. intermolecular hydrogen bonding. CrystEngComm 2020, 22, 628-633. [CrossRef] 
22. Hristova, S.; Kamounah, F.S.; Molla, N.; Hansen, P.E.; Nedeltcheva, D.; Antonov, L. The possible tautomerism of the potential rotary switch 2-(2-(2-Hydroxy-4-nitrophenyl)hydrazono)-1-phenylbutane-1,3-dione. Dye. Pigment. 2017, 144, 249-261. [CrossRef]

23. Lycka, A. 15 N NMR study of (E)- and (Z)-2-(2-(2-hydroxy-4-nitrophenyl)hydrazono)-1-phenylbutane-1,3-diones. A suitable method for analysis of hydrazone isomers. Dye. Pigment. 2018, 150, 181-184. [CrossRef]

24. Hristova, S.; Kamounah, F.S.; Crochet, A.; Hansen, P.E.; Fromm, K.M.; Nedeltcheva, D.; Antonov, L. Isomerization and aggregation of 2-(2-(2-hydroxy-4-nitrophenyl)hydrazono)-1-phenylbutane-1,3-dione: Recent evidences from theory and experiment. J. Mol. Liq. 2019, 283, 242-248. [CrossRef]

25. Gawinecki, R.; Kolehmainen, E.; Janota, H.; Kauppinen, R.; Nissinen, M.; Osmialowski, B. Predominance of 2-arylhydrazones of 1,3-diphenylpropane-1,2,3-trione over its proton-transfer products. J. Phys. Org. Chem. 2001, 14, 797-803. [CrossRef]

26. Antonov, L. Absorption UV-Vis Spectroscopy and Chemometrics: From Qualitative Conclusions to Quantitative Analysis. In Tautomerism; Antonov, L., Ed.; Wiley-VCH Verlag GmbH \& Co. KGaA: Weinheim, Germany, 2013; pp. 25-47.

27. Nedeltcheva, D.; Antonov, L.; Lycka, A.; Damyanova, B.; Popov, S. Chemometric Models For Quantitative Analysis of Tautomeric Schiff Bases and Azo Dyes. Curr. Org. Chem. 2009, 13, 217-240. [CrossRef]

28. Steiner, T. The Hydrogen Bond in the Solid State. Angew. Chem. Int. Ed. 2002, 41, 48-76. [CrossRef]

29. Jeffrey, G. An Introduction to Hydrogen Bonding; Oxford University Press: Oxford, UK, 1997.

30. Kopylovich, M.N.; Mahmudov, K.T.; Haukka, M.; Luzyanin, K.V.; Pombeiro, A.J.L. (E)-2-(2-(2-hydroxyphenyl)hydrazono)-1-phenylbutane-1,3-dione: Tautomery and coordination to copper(II). Inorg. Chim. Acta 2011, 374, 175-180. [CrossRef]

31. Bertolasi, V.; Nanni, L.; Gilli, P.; Ferretti, V.; Gilli, G.; Issa, Y.; Sherif, O. Intramolecular N-H. O=C hydrogen-bonding assisted by resonance-Intercorrelation between structural and spectroscopic data for 6 beta-diketo-arylhydrazones derived from benzoylacetone or acetylacetone. New J. Chem. 1994, 18, 251-261.

32. Eliseeva, S.V.; Minacheva, L.K.; Kuz'Mina, N.P.; Sergienko, V.S. Crystal structure of p-carboxyphenylhydrazone benzoylacetone. Crystallogr. Rep. 2005, 50, 85-88. [CrossRef]

33. Dolomanov, O.; Bourhis, L.J.; Gildea, R.; Howard, J.A.; Puschmann, H. OLEX2: A complete structure solution, refinement and analysis program. J. Appl. Crystallogr. 2009, 42, 339-341. [CrossRef]

34. Sheldrick, G.M. SHELXT - integrated space-group and crystal-structure determination. Acta Crystallogr. Sect. A Found. Adv. 2015, A71, 3-8. [CrossRef] [PubMed]

35. Sheldrick, G.M. Crystal structure refinement with SHELXL. Acta Crystallogr. Sect. C Struct. Chem. 2015, C71, 3-8. [CrossRef] [PubMed]

36. Frisch, M.; Trucks, G.; Schlegel, H.; Scuseria, G.; Robb, M.; Cheeseman, J.; Scalmani, G.; Barone, V.; Mennucci, B.; Petersson, G.; et al. Gaussian 09 Revision D.01; Gaussian, Inc.: Wallingford, CT, USA, 2013.

37. Zhao, Y.; Truhlar, D. Density Functionals with Broad Applicability in Chemistry. Acc. Chem. Res. 2008, 41, 157-167. [CrossRef] [PubMed]

38. Zhao, Y.; Truhlar, D. The M06 suite of density functionals for main group thermochemistry, thermochemical kinetics, noncovalent interactions, excited states, and transition elements: Two new functionals and systematic testing of four M06 functionals and 12 other functionals. Theor. Chem. Acc. 2008, 120, 215-241. [CrossRef]

39. Weigend, F.; Ahlrichs, R. Balanced basis sets of split valence, triple zeta valence and quadruple zeta valence quality for H to Rn: Design and assessment of accuracy. Phys. Chem. Chem. Phys. 2005, 7, 3297-3305. [CrossRef]

40. Kawauchi, S.; Antonov, L. Description of the Tautomerism in Some Azonaphthols. J. Phys. Org. Chem. 2013, 26, 643-652. [CrossRef]

41. Manolova, Y.; Kurteva, V.B.; Antonov, L.; Marciniak, H.; Lochbrunner, S.; Crochet, A.; Fromm, K.M.; Kamounah, F.S.; Hansen, P.E. 4-Hydroxy-1-naphthaldehydes: Proton transfer or deprotonation. Phys. Chem. Chem. Phys. 2015, 17, 10238-10249. [CrossRef]

42. Manolova, Y.; Marciniak, H.; Tschierlei, S.; Fennel, F.; Kamounah, F.S.; Lochbrunner, S.; Antonov, L. Solvent control of intramolecular proton transfer: Is 4-hydroxy-3-(piperidin-1-ylmethyl)-1-naphthaldehyde a proton crane? Phys. Chem. Chem. Phys. 2017, 19, 7316-7325. [CrossRef]

43. Tomasi, J.; Mennucci, B.; Cammi, R. Quantum Mechanical Continuum Solvation Models. Chem. Rev. 2005, 105, 2999-3094. [CrossRef] 
44. Improta, R. UV-Visible Absorption and Emission Energies in Condensed Phase by PCM/TD-DFT Methods. In Computational Strategies for Spectroscopy; Barone, V., Ed.; John Wiley \& Sons, Inc.: Hoboken, NJ, USA, 2011; pp. 37-75.

45. Antonov, L.; Kawauchi, S.; Okuno, Y. Prediction of the Color of Dyes by Using Time-Dependent Density Functional Theory. Bulg. Chem. Commun. 2014, 46, 228-237.

46. Jacquemin, D.; Mennucci, B.; Adamo, C. Excited-state calculations with TD-DFT: From benchmarks to simulations in complex environments. Phys. Chem. Chem. Phys. 2011, 13, 16987-16998. [CrossRef] [PubMed]

(C) 2020 by the authors. Licensee MDPI, Basel, Switzerland. This article is an open access article distributed under the terms and conditions of the Creative Commons Attribution (CC BY) license (http://creativecommons.org/licenses/by/4.0/). 